\title{
How many kinds of visceral afferents?
}

\author{
M Costa, S H J Brookes, V Zagorodnyuk
}

Gut 2004;53(Suppl II):ii1-ii4. doi: 10.1136/gut.2003.033407

Most afferent signals from the viscera do not give rise to conscious experience and yet they participate in the complex neural control of visceral functions. Surprisingly little information is available on the origin, morphology, and receptor functional characteristics of the nerve endings of most primary afferent neurones to the digestive tract. This review deals with the morphological nature of the afferent neurones that supply the gastrointestinal tract specifically.
See end of article for authors' affiliations .....................

Correspondence to: Professor M Costa, Department of Physiology, School of Medicine, Flinders University, PO Box 2100, Adelaide 5001, SA, Australia; marcello. costa@flinders.edu.au

\section{SUMMARY}

Most afferent signals from the viscera do not give rise to conscious experience and yet they participate in the complex neural control of visceral functions. Studies of the extrinsic visceral afferent nerves supplying the digestive tract have been hampered because their nerve endings are intermingled with the extensive net of nerve fibres from the enteric nervous system, which also contains intrinsic primary afferent neurones (IPANs). The extrinsic afferent neurones (EPANs) to the digestive tract are unmyelinated and are located either in vagal or spinal ganglia where they are mixed with somatic afferent neurones and reach the gut via vagal, splanchnic, pelvic, and pudendal nerves. Anterograde fillings in vivo and in vitro have been used to reveal the mode of termination within the gut wall. The nerve endings of vagal afferents in the stomach are intraganglionic laminar endings (IGLEs) or intramuscular arrays (IMAs) and these supply almost all of the digestive tract. IGLEs are the site of mechanosensory transduction. Similar IGLEs supply the rectum (rectal IGLEs) running in the pelvic nerves. Spinal afferent neurones terminate as free nerve endings within the different gut layers. Different neurochemicals are present in the visceral afferents to the digestive tract but little is known of their specific function. Mucosal visceral afferent nerve fibres are activated and modulated by substances such as serotonin and cholecystokinin, released from mucosal enteroendocrine cells. Spinal visceral afferents provide collaterals to enteric and prevertebral ganglia and blood vessels where they are likely to play an efferent function. Intestinofugal neurones provide another source of neural activity that leaves the digestive tract to affect neurones in prevertebral ganglia and in the spinal cord. Identification of afferent nerve endings in the digestive tract and the correlation with their function is in its infancy.

\section{INTRODUCTION}

Only in specific circumstances do humans appear to have conscious experience of internal organs and yet the central nervous system is continuously bombarded by ongoing afferent traffic from viscera that is not associated with conscious experience. ${ }^{1}$ This implies that most visceral afferent signals do not give rise to conscious perception. The primary afferent neurones that detect bodily functions can be distinguished as somatic and visceral. Those supplying blood vessels may be regarded as a separate component because of the ubiquitous nature of the blood supply.

This short review deals with the morphological nature of the afferent neurones that supply the gastrointestinal tract specifically. The major difficulty encountered by investigators in identifying the primary afferent neurones and their endings is that the digestive tract contains an extensive network of intrinsic neurones able to operate independently from the central nervous system. This "independent" enteric nervous system is composed of circuits that include intrinsic afferent neurones. Thus there are two types of afferent neurone involved in gastrointestinal functions-namely, IPANs, which are part of the enteric nervous system, and EPANS. Their nerve endings are mostly indistinguishable on the basis of their morphology. Similarly, the nerve endings of the axons of other enteric interand motor neurones, as well as the endings of the extrinsic preganglionic sympathetic and parasympathetic neurones that terminate within the gut wall, are mixed with the primary afferent nerve endings. Unravelling of these important nerve endings from the multitude of other nerve endings is in its infancy.

\section{STRATEGIES FOR IDENTIFICATION OF EPANS}

Axons of EPANs reach the digestive tract within nerve bundles. The major afferent connections occur via the vagus nerve (vagal afferent pathways), via the mesenteric nerves and the thoracic and lumbar splanchnics (spinal afferent pathways), and via the pelvic and pudendal nerves (sacral spinal afferent pathways). Most nerve fibres are unmyelinated. ${ }^{23}$ Two different

Abbreviations: IPANs, intrinsic primary afferent neurones; EPANs, extrinsic primary afferent neurones; IGLEs, intraganglionic laminar endings; CGRP, calcitonin gene related peptide; IMA, intramuscular array; SP, substance $P$; CNS, central nervous system 
questions arise with the extrinsic visceral afferents. Firstly, there is the question of where the nerve cell bodies of origin are located. The second relates to the structure and distribution of the nerve endings within the gut wall. The major problem in identifying the extrinsic afferent nerve endings, with the exception of some specialised terminals in the upper digestive tract and in the anal canal, has been that the other terminals may have no special morphological features that distinguish them from efferent or enteric nerve terminals.

There are several strategies to address these problems. Traditionally, the origin of neuronal pathways has been tackled with lesion studies to detect degeneration of nerve terminals when disconnected from their cell bodies of origin. However, degeneration of terminals after extrinsic denervation in the intestinal wall is hard to demonstrate. ${ }^{2}$ In addition, extrinsic efferent nerve fibres also degenerate.

More recently, tracing studies have become the most effective way to study the origin of extrinsic afferent nerve terminals in the digestive tract. Only recently, retrograde and anterograde tracing techniques have been applied to these pathways. Retrograde labelling from the digestive tract confirms that the cell bodies are located in the nodose (vagal afferents) and dorsal root ganglia (spinal and sacral afferents). In these ganglia, they are mixed with all other primary afferent neurones supplying other viscera and blood vessels of the body wall (somatic). There appears to be no regional-topical distribution of the nerve cells. Also, each sensory ganglion supplies a large portion of the digestive tube. Anterograde tracing in vivo is performed by injecting neuronal markers into the sensory ganglia. These are then taken up by the nerve cells and transported to their terminals. The techniques have been pioneered in the laboratory of Terry Powley and Hans Berthoud, and have revealed for the first time details of sensory innervation of the gastrointestinal tract.

A modification of anterograde tracing suitable for visualising nerve endings of severed afferent axons has been developed in our laboratory for studies in vitro. ${ }^{4}$ This technique has been used to study extrinsic afferent terminals in the oesophagus and stomach.

Another strategy for localisation of primary afferent neurones is the use of histochemistry. If the chemical coding - that is, the specific combination of neurochemicals that are present in a functional class of primary afferent neurones-is established, the distribution of the specific markers can be used to map the distribution of these nerve terminals in the digestive tract. For example, the presence of the peptide calcitonin gene related peptide (CGRP) in a proportion of spinal afferent neurones to the guinea pig small intestine enabled the distribution of these fibres to be described. $^{5}$

\section{EXTRINSIC AFFERENT INNERVATION OF THE UPPER GASTROINTESTINAL TRACT}

Using anterograde tracing methods in vivo, the oesophagus and stomach were found to be supplied by primary afferent neurones located in the nodose ganglia. ${ }^{6-8}$ Vagal afferent fibres form specialised nerve endings within the myenteric ganglia, termed IGLEs. These are distributed fairly homogeneously along the entire length of the oesophagus in the species studied so far (rat and mouse). In the rat, some similar structures have been reported in the mucosa of the upper oesophagus not associated with enteric ganglia. ${ }^{9}$ In the guinea pig oesophagus, IGLEs have been demonstrated to be the mechanosensitive terminals responsible for the stretch induced afferent activity. ${ }^{10}$ The stomach is also supplied by similar afferent nerve terminals of vagal origin. ${ }^{67}$ In the guinea pig, IGLEs are the site of transduction for passive and active mechanical tension. ${ }^{11}$ Their nerve endings are mainly located on the surface of ganglia with some lamellar endings deep in the ganglia. ${ }^{12}$ They have a high density of mitochondria. ${ }^{13}$ An important type of primary afferent nerve ending of vagal origin is the IMA. ${ }^{67}$ These endings are more dense in the pyloric sphincter region. Despite their proposed role as tension receptors, ${ }^{14}{ }^{15}$ evidence for this hypothesis is still lacking. Club-like afferent nerve endings of vagal origin are present in the thick muscle of the antrum. The stomach is also supplied by capsaicin sensitive spinal afferent fibres, identified tentatively as containing tachykinins and CGRP. Varicose nerve terminals appear to meander within the layers and enteric ganglia, with no specialised nerve endings. ${ }^{16}{ }^{17}$

\section{SMALL INTESTINE}

IGLEs and IMAs of vagal origin become more sparse along the small intestine. ${ }^{6}$ After the first suggestions based on lesion studies, ${ }^{18}$ anterograde tracing in vivo demonstrated that, in the mucosa, there are also primary afferent nerve endings of vagal origin. ${ }^{19}$ The spinal primary afferent neurones also supply the small intestine with terminals in the enteric ganglia and in the mucosa. ${ }^{3}$ However, up until now only one paper using an early method for anterograde tracing was published. ${ }^{20}$

\section{LARGE INTESTINE}

There are still primary afferent fibres of vagal origin that reach the large intestine forming IGLEs $^{6}$ and similarly, spinal afferent neurones supply the enteric plexuses and the mucosa of the colon. ${ }^{21} 22$ Afferent fibres from the colon reach the spinal cord via the lumbar colonic, hypogastric, and pelvic nerves. ${ }^{23}$ The rectum and anal canal appear to receive the extrinsic afferent supply via the pelvic and pudendal nerves. ${ }^{24-26}$ Recent results show that there are special nerve endings similar to IGLEs (rectal IGLEs) which are sensitive to local mechanical stimuli and reaching the rectum via the pelvic nerves. ${ }^{27}$ Earlier report of afferent nerve endings in the anal region in humans came from Duthie and Gairns. ${ }^{24}$ They described free corpuscolated nerve endings (Meissner, Krause, Golgi-Mazzoni, and other less definite endings) in the epithelium of the perianal skin and of the anal canal. Pacinian corpuscles are also present in human and cat mesentery. ${ }^{28}$

\section{CHEMICAL CODING}

One of the most useful concepts developed from the explosion of neurochemical markers found in neurones by histochemical methods is the idea of chemical coding. It appears that functionally distinct classes of neurones are characterised by specific combinations of neurochemicals, some of which may be directly related to their transmitter functions, others to less clear properties. ${ }^{29}$ The combination of neurochemicals varies significantly between regions of the body and species. The digestive EPANs are no exception. Some neuropeptides, including substance P (SP) and CGRP, have been demonstrated in spinal primary afferent neurones supplying viscera, including the intestine. ${ }^{3031}$ Other neuropeptides are also present in some visceral sensory neurones. ${ }^{32}$ Chemical coding of spinal and vagal afferents is different. In the guinea pig, less than $10 \%$ of vagal afferents have the peptides CGRP, SP, or somatostatin..$^{33}$ IGLEs contain calretinin and calbindin in the rat but not in the guinea pig. ${ }^{9}{ }^{10}{ }^{34} \mathrm{~A}$ calcium binding protein, neurocalcin, has been demonstrated in rat IGLEs. ${ }^{12}$ CGRP is present in IGLEs of the ferret (unpublished observations).

Among the many classes of molecules present on primary afferent endings that are likely to be determinant in the chemical coding are pharmacological receptors, ion, chemicoand mechano sensitive channels, calcium binding proteins, 
and surface markers such as lectin binding sites, etc. For instance, in the rat there are at least two classes of small size spinal afferent neurones, namely those with neuropeptides and those with IB-4 lectin binding, but no neuropeptides, and with a high density of the tetrodotoxin resistant channel. ${ }^{35}{ }^{36}$ The functional significance of the different calcium binding proteins is unclear although they may be involved in buffering cytoplasmic calcium, thus modulating calcium dependent potassium channels involved in afterhyperpolarisation.

Another difference in the extrinsic primary afferents is their dependence on growth factors. For instance, the neuropeptide containing spinal afferents in rats depend for their survival on nerve growth factor whereas IB4 positive neurones are dependent on glial derived neurotrophic factor. ${ }^{35}$ More recently, it was shown that IGLEs in the mouse small intestine, but not those in the stomach, are sensitive to a deficiency in neurotrophin- $4 .{ }^{37}$ The $N$-methyl-Daspartate glutamate receptor appears to be selectively localised on some spinal afferents to the colon. ${ }^{38}$ Mouse vagal IGLEs are immunoreactive for the P2X2 receptor (fig 1$)^{39}$

\section{RELATION BETWEEN PRIMARY AFFERENT FIBRES AND INTERSTITIAL CELLS OF CAJAL}

In addition to their role as pacemaker cells and probably as intermediaries of nerve mediated motor excitation and inhibition of intestinal smooth muscle, the interstitial cells of Cajal have been proposed to be specifically associated with the nerve endings of IMAs ${ }^{37}$ and with possible interstitial cells in the mucosa, ${ }^{19}$ and are thus potentially involved in afferent neural transduction. This fascinating possibility is one of the issues that needs to be clarified in future experiments.

\section{RELATION BETWEEN PRIMARY AFFERENT FIBRES AND PARACRINE MUCOSAL CELLS}

Primary afferent mucosal endings come in close proximity to many of the mucosal endocrine cells. Substances released from these cells by a variety of chemical and mechanical stimuli are also likely to act locally before entering the circulation. Nerve endings of IPANs and EPANs form one of the natural targets. ${ }^{40}$ This possibility has been demonstrated for two such cell types. Cholecystokinin and the serotonin containing mucosal paracrine cells have been shown to activate vagal afferent neurones. ${ }^{41} 42$

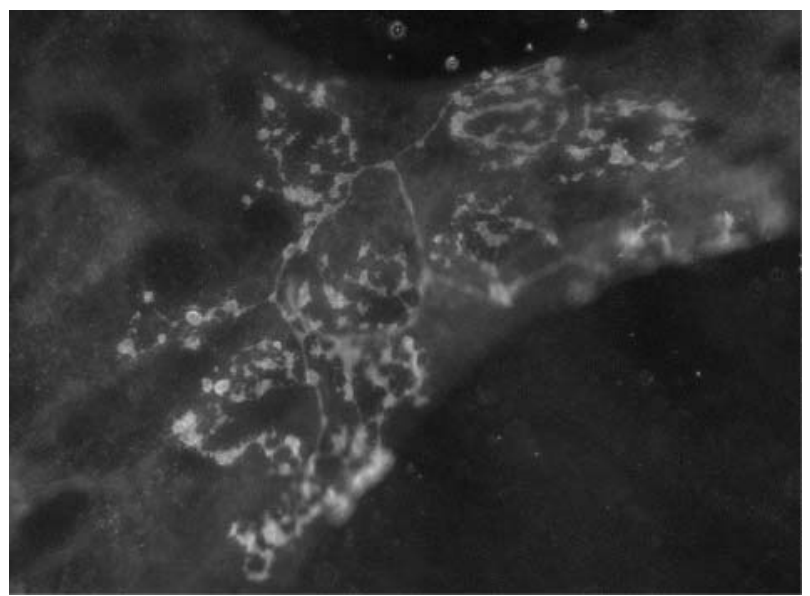

Figure 1 Whole mount preparation of mouse stomach with an intraganglionic laminar ending showing P2X2 receptor immunoreactivity.

\section{EFFERENT FUNCTION OF PRIMARY AFFERENTS}

Branching of primary afferent neurones suggests that action potentials which invade the branches antidromically may release transmitter substances from the peripheral endings. This has been shown to be the case for some of the peptide containing spinal afferent fibres. Collaterals of spinal afferent fibres cause release of peptides onto myenteric neurones and blood vessels.

A similar function has been suggested for some of the vagal afferent neurones. IGLE nerve endings form close connections with enteric neurones in the myenteric ganglia. In spite of some initial indications, there is little evidence that their activation leads to activity of myenteric neurones.

\section{INTESTINOFUGAL NEURONES}

Since the suggestion of Kunz and Saccomanno ${ }^{43}$ that there are neurones with cell bodies in the enteric ganglia projecting to the prevertebral ganglia, these pathways have been extensively investigated. ${ }^{44}{ }^{45}$ Also of potential importance for afferent information from the gut to the CNS are the rectospinal neurones whose cell bodies in the enteric ganglia project directly to the sacral spinal cord. ${ }^{46}$

\section{CONCLUSIONS}

Surprisingly little information is available on the origin, morphology, and receptor functional characteristics of the nerve endings of most primary afferent neurones to the digestive tract. Even more surprising is the lack of identification of neurochemical markers in a vast population of primary afferents. The explosion of neurochemicals found in afferent neurones represents both a challenge and a unique opportunity to investigate ways to intervene in diseases involving primary visceral afferent pathways.

\section{Authors' affiliations}

M Costa, S H J Brookes, V Zagorodnyuk, Department of Physiology and Centre of Neuroscience, School of Medicine, Flinders University,

Adelaide, Australia

\section{REFERENCES}

1 Kern S. Cerebral cortical registration of subliminal visceral stimulation. Gastroenterology 2002;122:290-8

2 Schofield GC. Anatomy of muscular and neural tissues in the alimentary canal. In: Code CF, ed. Handbook of physiology, vol 4. Washington DC: American Physiology Society, 1968;1579-628)

3 Cervero F, Sharkey KA. An electrophysiological and anatomical study of intestinal afferent fibres in the rat. J Physiol 1988;401:381-97.

4 Tassicker BC, Hennig GW, Costa M, et al. Rapid anterograde and retrograde tracing from mesenteric nerve trunks to the guinea-pig small intestine in vitro. Cell Tissue Res 1999;295:437-52.

5 Gibbins IL, Furness JB, Costa M, et al. Co-localisation of calcitonin generelated peptide-like immunoreactivity with substance $P$ in cutaneous, vascular and visceral sensory neurons of guinea pigs. Neurosci Lett 1985;57:125-30.

6 Wang FB, Powley TL. Topographic inventories of vagal afferents in gastrointestinal muscle. J Comp Neurol 2000;421:302-24

7 Berthoud HR, Neuhuber WL. Functional and chemical anatomy of the afferen vagal system. Auton Neurosci 2000;85:1-17.

8 Fox EA Phillips RJ, Martinson FA, et al. Vagal afferent innervation of smooth muscle in the stomach and duodenum of the mouse: morphology and topography. J Comp Neurol 2000;428:558-76.

9 Dutsch M, Eichhorn U, Worl J, et al. Vagal and spinal afferent innervation of the rat esophagus: a combined retrograde tracing and immunocytochemical study with special emphasis on calcium-binding proteins. J Comp Neurol 1998;398:289-307.

10 Zagorodnyuk VP, Brookes SJH. Transduction sites of vagal mechanoreceptors in the guinea pig esophagus. J Neurosci 2000;20:6249-55.

11 Zagorodnyuk VP, Chen BN, Brookes SJH. Intraganglionic laminar endings are mechano-transduction sites of vagal tension receptors in the guinea-pig stomach. J Physiol (Lond) 2001;534:255-68.

12 lino S, Kato M, Hidaka $\mathrm{H}$, et al. Neurocalcin-like immunoreactivity in the rat esophageal nervous system. Cell Tissue Res 1998;294:57-68.

13 Neuhuber WL. Sensory vagal innervation of the rat esophagus and cardia: a light and electron microscope anterograde tracing study. J Auton Nerv Syst 1987;20:243-55

14 Berthoud HR, Powley TL. Vagal afferent innervation of the rat fundic stomach: morphological characterization of the gastric tension receptor. J Comp Neurol $1992 \cdot 319 \cdot 261-76$ 
15 Phillips RJ, Powley TL. Tension and stretch receptors in gastrointestinal smooth muscle: re-evaluating vagal mechanoreceptor electrophysiology. Brain Res $\operatorname{Rev} 2000 ; 34: 1-26$

16 Sharkey KA, Williams RG, Dockray GJ. Sensory substance P inneration of the stomach and pancreas. Demonstration of capsaicin-sensitive sensory neurons in the rat by combined immunohistochemistry and retrograde tracing. Gastroenterology 1984;87:914-21.

17 Green T, Dockray G. Characterization of the peptidergic afferent innervation of the stomach in the rat, mouse and guinea-pig. Neuroscience 1988;25:181-93.

18 Schofield GC. Experimental studies on the innervation of the mucous membrane of the gut. Brain 1960;83:490-514.

19 Berthoud HR, Kressel M, Raybould HE, et al. Vagal sensors in the rat duodenal mucosa: distribution and structure as revealed by in vivo Dil-tracing. Anat Embryol 1995;191:203-12.

20 Aldskogius H, Elfvin LG, Forsman CA. Primary sensory afferents in the inferior mesenteric ganglion and related nerves of the guinea pig. An experimental study with anterogradely transported wheat germ agglutinin-horseradish peroxidase conjugate. J Auton Nerv Syst 1986;15:179-90.

21 Janig W, McLachlan EM. Organization of lumbar spinal outflow to distal colon and pelvic organs. Physiol Rev 1987;67:1332-404.

22 Lynn PA, Blackshaw LA. In vitro recordings of afferent fibres with receptive fields in the serosa, muscle and mucosa of rat colon. J Physiol 1999;518:271-82.

23 Janig W, Koltzenburg M. On the function of spinal primary afferent fibres supplying colon and urinary bladder. J Auton Nerv Syst 1990;30:S89-96.

24 Duthie HL, Gairns FW. Sensory nerve-endings and sensation in the anal region of man. Br J Surg 1960;46:585-95.

25 Kawatani M, Nagel J, de Groat WC. Identification of neuropeptides in pelvic and pudendal nerve afferent pathways to the sacral spinal cord of the cat. J Comp Neurol 1986;249:117-32.

26 Thor KB, Morgan C, Nadelhaft I, et al. Organization of afferent and efferent pathways in the pudendal nerve of the female cat. J Comp Neurol 1989;288:263-79.

27 Lynn PA, Olsson C, Zagorodnyuk V, et al. Rectal intraganglionic laminar endings are transduction sites of extrinsic mechanoreceptors in the guinea pig rectum. Gastroenterology 2003;125:786-94.

28 Sheehan $\mathbf{D}$. The afferent nerve supply of the mesentery and its significance in the causation of abdominal pain. J Anat 1933;67:233-49.

29 Costa M, Furness JB, Gibbins IL. Chemical coding of enteric neurons. Prog Brain Res 1986:68:217-19.

30 Dockray GJ, Sharkey KA. Neurochemistry of visceral afferent neurons. Prog Brain Res 1986;67:133-48.

31 Gibbins IL, Furness JB, Costa M. Pathway-specific patterns of the co-existence of substance $P$, calcitonin gene-related peptide, cholecystokinin and dynorphin in neurons of the dorsal root ganglia of the guinea-pig. Cell Tissue Res 1987;248:417-37.

32 Fahrenkrug J, Hannibal J. PACAP in visceral afferent nerves supplying the rat digestive and urinary tract. Regul Pept 1997;71:110.

33 Green T, Dockray GJ. Calcitonin gene-related peptide and substance P in afferents to the upper gastrointestinal tract in the rat. Neurosci Lett 1987;76:151-6.

34 Kuramoto H, Kuwano R. Immunohistochemical demonstration of calbindin containing nerve endings in the rat esophagus. Cell Tissue Res 1994;278:57-64

35 Stucky CL, Lewin GR. Isolectin B(4)-positive and -negative nociceptors are functionally distinct. J Neurosci 1999; 19:6497-505.

36 Fjell J, Hielmstrom P, Hormuzdiar W, et al. Localization of the tetrodotoxinresistant sodium channel $\mathrm{NaN}$ in nociceptors. Neuroreport 2000;11:199-202.

37 Fox EA, Phillips RJ, Baronowsky EA, et al. Neurotrophin-4 deficient mice have a loss of vagal intraganglionic mechanoreceptors from the small intestine and a disruption of short-term satiety. J Neurosci 2001;21:8602-15.

38 McRoberts JA, Coutinho SV, Marvizon JC, et al. Role of peripheral N-methylD-aspartate (NMDA) receptors in visceral nociception in rats. Gastroenterology 2001;120:1737-48

39 Castelucci P, Robbins HL, Furness JB. P2X2 purine receptor immunoreactivity of intraganglionic laminar endings in the mouse gastrointestinal tract. Cell Tissue Res 2003:312:167-74.

40 Raybould HE. Nutrient tasting and signaling mechanisms in the gut. I. Sensing of lipid by the intestinal mucosa. Am J Physiol 1999;277:G751-5.

41 Raybould HE, Zittel TT, Holzer HH, et al. Gastroduodenal sensory mechanisms and CCK in inhibition of gastric emptying in response to a meal. Dig Dis Sci 1994;39:41s-3.

42 Zhu JX, Wu XY, Owyang C, et al. Intestinal serotonin acts as a paracrine substance to mediate vagal signal transmission evoked by luminal factors in the rat. J Physiol 2001;530:431-42.

43 Kunz A, Saccomanno G. Reflex inhibition of intestinal motility mediated through decentralized prevertebral ganglia. J Neurophysiol 1944;7:163-70.

44 Sharkey KA, Lomax AEG, Bertrand PP, et al. Electrophysiology, shape, and chemistry of neurons that project from guinea pig colon to inferior mesenteric ganglia. Gastroenterology 1998;115:909-18.

45 Luckensmeyer GB, Keast JR. Immunohistochemical characterisation of viscerofugal neurons projecting to the inferior mesenteric and major pelvic ganglia in the male rat. J Auton Nerv Syst 1996:61:6-16.

46 Doerffler MJ, Neuhuber WL. Rectospinal neurons: evidence for a direct projection from the enteric to the central nervous system in the rat. Neurosci Lett 1988;92:121-5. 